Najipah - Penerapan Support Vector Regression (SVR) Untuk Peramalan Inflasi Bulanan Nasional

\title{
PENERAPAN SUPPORT VECTOR REGRESSION (SVR) UNTUK PERAMALAN INFLASI BULANAN NASIONAL
}

\author{
Husnul Khatimi' ${ }^{1)}$, Muhammad Alkaff ${ }^{2)}$, dan Dewi Rizqia Najipah ${ }^{3)}$ \\ Program Studi Teknologi Informasi Fakultas Teknik, Universitas Lambung Mangkurat \\ Jl. Brigjen H. Hasan Basri, Kayu Tangi, Banjarmasin, Indonesia 70123 \\ e-mail: hkhatimi@ulm.ac.id ${ }^{1}$,m.alkaff@ulm.ac.id,19dewi@gmail.com³
}

\begin{abstract}
Abstrak
Peramalan tingkat inflasi menjadi penting untuk bisa membantu pemerintah dalam membuat kebijakan sebagai upaya menjaga stabilitas inflasi. Metode yang digunakan pada penelitian ini adalah Support Vector Regression (SVR) menggunakan input inflasi umum serta inflasi yang diukur dengan IHK yang dikelompokkan berdasarkan kelompok. Hasil model prediksi yang paling baik dari percobaan terhadap data inflasi menurut kelompok komoditi dengan menggunakan metode SVR (Support Vector Regression) yaitu model dengan kombinasi parameter $C$ sebesar 0,37, epsilon ( $\varepsilon$ sebesar 0,001 dan gamma $(\gamma)$ sebesar 12,5365 dengan nilai RMSE terhadap data validasinya sebesar 0.0011, dan nilai RMSE terhadap data testingnya sebesar 0.0477 dengan nilai $R^{2}$ terhadap data validasinya sebesar 0.9999 ,
\end{abstract}

Kata Kunci : peramalan; inflasi; support vector regression (SVR), RMSE

\begin{abstract}
Forecasting the inflation is important in order to assist government in taking policy as an effort to maintain inflation stability.This study aims to forecast monthly inflation in Indonesia using general inflation and inflation that divided into 7 expenditure categories where the overall data can be obtained from Badan Pusat Statistik. The method used to forecast inflation is Support Vector Regression (SVR) with RBF kernel. RMSE value of 0,0011 was obtained from the test result using validation data and 0,0477 using testing data with value of parameter $C$ is 0,37, value of parameter epsilon ( $\varepsilon$ ) is 0,001 and value of parameter gamma $(\gamma)$ is 12,5365 with value of $R^{2}$ using validation data is 0,9999 .
\end{abstract}

Keywords: forecasting; inflation; support vector regression (SVR), RMSE

\section{Pendahuluan}

I

nflasi dapat diartikan sebagai presentase kenaikan harga dari beberapa barang maupun jasa yang dikonsumsi rumah tangga secara umum. Beberapa barang maupun jasa dapat mengalami kenaikan harga sementara beberapa yang lain mengalami penurunan namun tidak menutup kemungkinan adanya barang yang harganya tidak berubah sama sekali dibandingkan dengan periode sebelumnya. Hitungan dari perubahan harga tersebut dicakup pada suatu indeks harga yang disebut dengan Indeks Harga Konsumen (IHK) atau Consumer Price Indeks (CPI).

Presentase kenaikan IHK disebut dengan nama inflasi, sementara deflasi merupakan kebalikan dari inflasi yaitu penurunan dari presentase kenaikan IHK [1]. Boediono menyatakan bahwa apabila kenaikan harga hanya berasal satu-dua barang maupun jasa saja, maka hal tersebut tidak dapat dikatakan sebagai inflasi. Menjadi pengecualian apabila kenaikan tersebut berkembang dan mengakibatkan kenaikan pada sebagian besar dari harga barang-barang maupun jasa lainnya. Dengan kata lain, inflasi dapat dikatakan sebagai proses menurunnya nilai mata uang secara berkelanjutan[1].

Inflasi dapat dijadikan sebagai indikator dalam mencerminkan kecenderungan umum tentang perubahan harga. Indikator ini nantinya dapat digunakan sebagai informasi dasar guna dilakukannya pengambilan keputusan baik itu tingkat ekonomi makro ataupun mikro, baik fiskal maupun moneter. Dalam cakupan yang lebih luas (makro) nilai inflasi mencerminkan kondisi atau stabilitas dari perekonomian dan moneter[2]. Sehingga menurut Endri untuk mrnganalisis perekonomian negara, inflasi dapat menjadi indikator yang sangat penting [3]. Berdasarkan hal tersebut maka peramalan tingkat inflasi menjadi penting untuk dapat membantu pemerintah dalam memutuskan kebijakan selaku upaya dalam menjaga stabilitas inflasi.

Beberapa metode dapat digunakan dalam peramalan, salah satunya adalah Support Vector Regression (SVR). SVR merupakan model pengembangan SVM dalam hal regresi di mana SVM diperkenalkan pertama kali sebagai konsep unggulan dalam bidang pengenalan pola, algoritma ini mampu memilih model otomatis juga tidak memiliki masalah dalam data training 
yang menghasilkan rasio kesalahan sangat kecil ketika dibandingkan (overfitting) dan menjadi populer berkat kesuksesannya dalam mengenali digit tulisan tangan dengan nilai error sebesar 1\%.[6][7][8].

Pada penelitian ini menggunakan input inflasi yang diukur dengan Inflasi yang dikelompokkan berdasarkan kelompok pengeluaran serta inflasi bulan sebelumnya. metode SVR dipilih sebagai metode yang akan diterapkan pada penelitian ini untuk meramalkan tingkat inflasi nasional di Indonesia.

\section{METODE PENELITIAN}

Bahan penelitian yang adalah data inflasi bulanan Indonesia. Alat yang digunakan pada penelitian ini adalah PC (Personal Computer) yang akan diimplementasikan sistem peramalan inflasi. Pada penelitian ini, sistem yang dibangun merupakan sistem berbasis website dengan penggunaan bahasa pemrograman Python versi 2.7.13.

Python memiliki beberapa framework khusus untuk membangun website, salah satunya adalah Flask Framework. Framework ini menyediakan website yang sederhana yang dapat diperluas dengan penambahan library yang sesuai dengan keperluan sistem. Flask yang digunakan pada penelitian ini adalah flask versi 0.12.2.

Editor yang digunakan dalam pembangunan sistem adalah salah satu Integrated Development Environment Python keluaran JetBrains yaitu Pycharm versi 172.3317.103. Software ini support dengan bahasa pemrograman Python dimana feature yang ditawarkan beragam.

Untuk menunjang pembuatan sistem agar dapat lebih mudah dikerjakan, ada beberapa library pendukung yang digunakan dalam pembangunan sistem ini. Diantaranya adalah Pandas 0.20.1. Library ini memungkinkan sistem untuk membaca dan menuliskan kembali file dengan ekstensi excel.

Selanjutnya ada Openpyx1 2.4.8. Library ini memungkinkan sistem untuk mengubah file excel tanpa menghilangkan data didalam excel tersebut yang sebelumnya tersimpan.

Kemudian ada Scikit-learn 0.18.1. Library ini merupakan library khusus machine learning pada Python dimana merupakan tools yang sederhana dan efisien untuk data mining dan data analysis. Scikit-learn dapat digunakan untuk kasus klasifikasi, regresi, clustering, hingga preprocessing. Pada penelitian ini, Scikit-learn yang digunakan hanya pada bagian regresi dimana algoritma yang digunakan adalah Support Vector Machine untuk kasus regresi yaitu Support Vector Regression (SVR), dan pada bagian preprocessing dengan MinMax Scaler sebagai modul untuk melakukan normalisasi dan denormalisasi data.

Data yang digunakan adalah data inflasi bulanan Indonesia [9] dan inflasi menurut kelompok pengeluaran[10] bulan Januari 2014 - Juli 2017 yang diambil dari situs resmi Badan Pusat Statistik. Data yang digunakan merupakan data sekunder yang dibagi menjadi dua bagian, yaitu data training mulai Januari 2014 sampai Mei 2017 dan data testing dari Mei 2017 sampai Juli 2017.

Dari keseluruhan data yang telah berhasil dikumpulkan dipisahkan antara data yang digunakan sebagai data training dan data testing. Selanjutnya pemrosesan menggunakan metode SVR akan dilakukan di mana data input dari data training akan dipetakan pada data outputnya sehingga model prediksi inflasi dengan SVR akan didapatkan. Input yang digunakan merupakan data 7 inflasi menurut kelompok pengeluaran dan inflasi umum bulan ke $n-1$ dengan output inflasi umum bulan ke-n.

data inflasi bulanan serta data 7 inflasi menurut kelompok pengeluaran yang sudah didapatkan mulai dari tahun 2014 hingga 2017 diupload kemudian dilakukan proses normalisasi terlebih dahulu sebelum dipisahkan menjadi data testing dan data training.

Dari data training yang ada yang dimulai dari Januari 2014 sampai dengan Mei 2017 akan diambil data validasinya yaitu dari April 2016 hingga Juli 2016. Adapun data testing merupakan data dari April hingga Juli 2017. Selanjutnya dilakukan mapping data input yaitu data 7 inflasi menurut kelompok komoditi beserta inflasi umum bulan ke-n ke data outputnya yaitu data inflasi umum bulan ke-n+1 dari data training melalui proses training oleh metode SVR.

Setelah model prediksi berhasil didapat dari proses training yang telah dilakukan sebelumnya, model akan digunakan untuk validasi model dengan data validasi yang ada untuk melihat kinerja pembelajaran dari proses training yang telah dilakukan. Apabila model yang didapat menghasilkan peramalan yang kurang baik terhadap data validasinya, maka proses pembelajaran diulangi lagi hingga didapatkan model yang sesuai. Kemudian data input testing yaitu data bulan April hingga Juni 2017 digunakan untuk melakukan prediksi. Setelah angka peramalan didapatkan maka dilakukan denormalisasi agar didapat prediksi inflasi April hingga Juni 2017, akurasi model akan diuji dengan nilai dari RMSE model tersebut serta membandingkan data hasil peramalan pada data testing dengan data sebenarnya. Dibawah ini dapat dilihat alur perancangan sistem. 


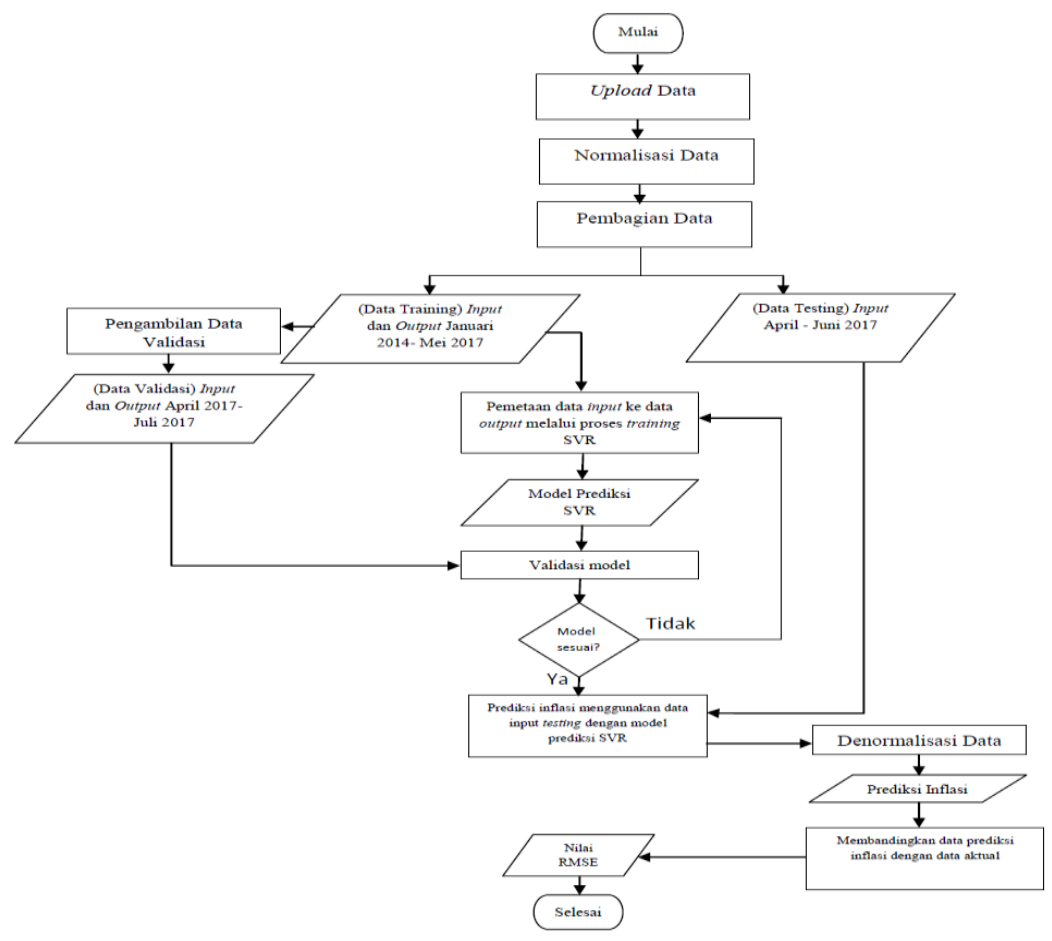

Gambar 1 Alur Perancangan Sistem

\section{HASIL DAN PEMBAHASAN}

Data yang sebelumnya telah didapatkan dari website Badan Pusat Statistik perlu diolah didalam sistem agar didapatkan hasil yang diinginkan. Beberapa proses perlu diterapkan sehingga sistem mampu mengolah data menjadi data yang diinginkan yang pada akhirnya akan menghasilkan output yang diperlukan dengan menggunakan Pycharm sebagai kode editornya.

Proses yang diperlukan pada sistem diantaranya adalah mendapatkan parameter, dimana proses tersebut dijalankan diluar sistem yang dibangun dan dapat dijalankan pada Pycharm dimana bertujuan untuk mendapatkan nilai parameter yang menghasilkan hasil peramalan yang baik dengan model yang sesuai.

Berdasarkan dari percobaan yang telah dilakukan terhadap data training Inflasi bulanan dengan menggunakan nilai parameter yang berbeda-beda maka dihasilkan model dengan tingkat akurasi yang berbeda-beda pula dengan rincian sebagai berikut.

Tabel 1.

Hasil Model Prediksi Inflasi dengan nilai C, Epsilon $(\varepsilon)$, dan Gamma $(\gamma)$ yang beragam

\begin{tabular}{|c|c|c|c|c|c|}
\hline \multicolumn{3}{|c|}{ Parameter } & \multirow{2}{*}{$\begin{array}{c}\mathrm{R}^{2} \\
\text { Validasi }\end{array}$} & \multirow{2}{*}{ RMSE Validasi } & \multirow{2}{*}{ RMSE Testing } \\
\hline C & $\begin{array}{c}\text { Epsilon } \\
(\varepsilon)\end{array}$ & $\begin{array}{c}\text { Gamma } \\
(\gamma)\end{array}$ & & & \\
\hline 1,0 & 1,0 & 1,0 & $-5,346$ & 0,355 & 0,414 \\
\hline 1,0 & 0,001 & 1,0 & 0,543 & 0,095 & 0,194 \\
\hline 0,1 & 0,001 & 1,0 & $-0,780$ & 0,188 & 0,137 \\
\hline 0,3 & 0,001 & 1,0 & $-0,242$ & 0,157 & 0,186 \\
\hline 0.37 & 0.001 & 1,0 & $-0,073$ & 0,146 & 0,190 \\
\hline 0.37 & 0.001 & 5,0 & 0,678 & 0,080 & 0,054 \\
\hline 0.37 & 0.001 & 10 & 0,997 & 0,006 & 0,048 \\
\hline 0.37 & 0.001 & 12 & 0.999 & 0.001 & 0.047 \\
\hline 0.37 & 0.001 & 12.5 & 0.999 & 0.001 & 0.047 \\
\hline 0.37 & 0.001 & 12,5365 & 0.999 & 0.001 & 0.047 \\
\hline
\end{tabular}

Kombinasi parameter terbaik berdasarkan percobaan diatas serta percobaan lain yang tidak terdokumentasikan disini didapatkan dengan nilai $C$ sebesar 0,37, epsilon $(\varepsilon)$ sebesar 0,001 dan gamma $(\gamma)$ sebesar 12,5365 dengan perbandingan data prediksi dan data aslinya yang terlihat pada Tabel berikut. 
Tabel 2

Hasil Kombinasi Parameter Terbaik

\begin{tabular}{|c|c|c|c|c|c|}
\hline Parameter & $\begin{array}{c}\text { Validasi } \\
\text { Asli }\end{array}$ & $\begin{array}{c}\text { Predilssi } \\
\text { Validasi }\end{array}$ & $\begin{array}{c}\text { Data } \\
\text { testing } \\
\text { Asli }\end{array}$ & $\begin{array}{c}\text { Prediksi } \\
\text { Testing }\end{array}$ & Hasil \\
\hline $\mathrm{C}=0,37$ & 0,24 & 0,24 & 0,39 & 0,30 & $\begin{array}{c}\mathrm{R}^{2} \text { Validasi } \\
0,9999\end{array}$ \\
\hline$(\varepsilon)=0,001$ & 0,66 & 0,65 & 0,69 & 0,69 & $\begin{array}{c}\text { RMSE Validasi } \\
0,0011\end{array}$ \\
\hline$(\gamma)=12,5365$ & 0,69 & 0,68 & 0,22 & 0,30 & $\begin{array}{c}\text { RMSE Testing } \\
0,0477\end{array}$ \\
\hline
\end{tabular}

Dari kombinasi parameter tersebut, didapatkan nilai $\mathrm{R}^{2}$ terhadap data validasinya sebesar 0.9999 , nilai RMSE terhadap data validasinya sebesar 0.0011, dan nilai RMSE terhadap data testingnya sebesar 0.0477. Adapun diagram perbandingan dari prediksi data validasi dari model yang dihasilkan dengan data validasi aslinya dapat dilihat seperti pada Gambar berikut.

\section{Prediksi Data Validasi}

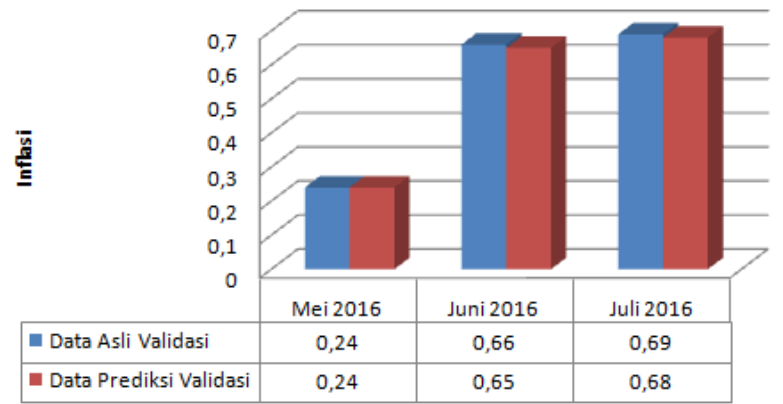

Gambar 2 Diagram Perbandingan Data Asli Validasi dan Data Prediksi Validasi

Seperti yang terlihat pada Gambar di atas, hasil prediksi terhadap data validasinya memiliki selisih yang kecil. Data asli validasi bulan pertama adalah sebesar 0,24 sementara data prediksi validasinya 0,24 . Data asli validasi bulan kedua adalah sebesar 0,66 sementara data prediksi validasinya adalah sebesar 0,65. Data asli validasi bulan ke-3 adalah sebesar 0,69 sementara data prediksi validasinya adalah sebesar 0,68 . Dengan hasil validasi diatas maka model dianggap cukup bagus untuk melakukan peramalan karena model dapat mengenali pola yang telah dipelajari sebelumnya dengan cukup baik sehingga hasil prediksi terhadap data validasinya tidak memiliki selisih yang signifikan. Adapun hasil prediksi terhadap data training dapat dilihat pada Gambar berikut.

\section{Prediksi Data Testing}

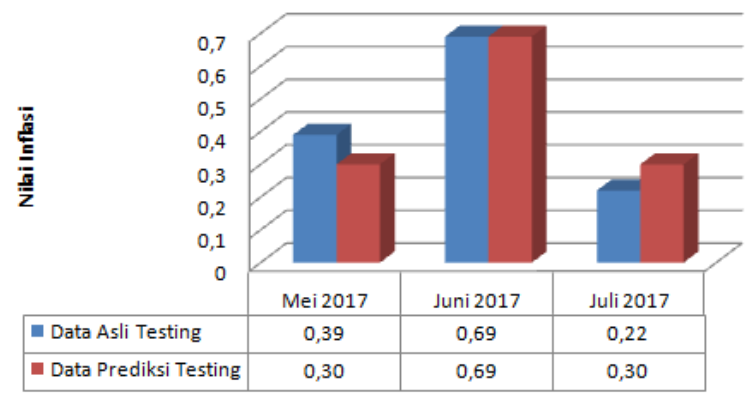

Gambar 3 Diagram Perbandingan Data Asli Testing dan Data Prediksi Testing

Seperti yang terlihat pada Gambar di atas, selisih hasil prediksi terhadap data testingnya dapat dilihat pada gambar 4.12 diatas. Data asli testing bulan pertama adalah sebesar 0,39 sementara data prediksi testingnya 0,30. Data asli testing bulan kedua adalah sebesar 0,69 sementara data prediksi testingnya adalah sebesar 0,69. Data asli validasi bulan ke-3 adalah sebesar 0,22 sementara data prediksi validasinya adalah sebesar 0,30. 
Berdasarkan metodologi yang telah dibahas sebelumnya, maka dihasikan Sistem Peramalan Inflasi Bulanan menggunakan Support Vector Regression. Untuk menjalankan web server dari Flask, app.py perlu dijalankan terlebih dahulu sehingga port 5000 akan terbuka dan menyediakan web server untuk Sistem yang telah dibuat. Untuk melihat hasil dari sistem yang telah dibangun, cukup mengetikkan url pada browser http://localhost:5000/, maka browser akan menampilkan halaman awal dari sistem. Adapun sistem terdiri dari halaman-halaman sebagai berikut:

1. Halaman Awal

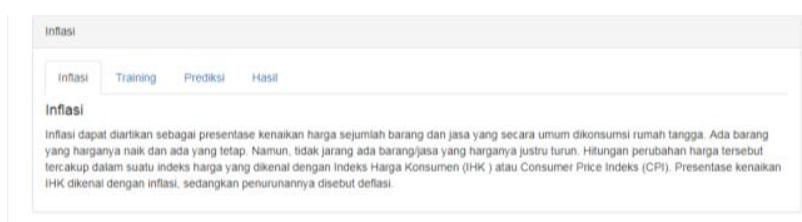

Gambar 4. Halaman Awal Sistem Prediksi

2. Halaman Training

3. Halaman Prediksi
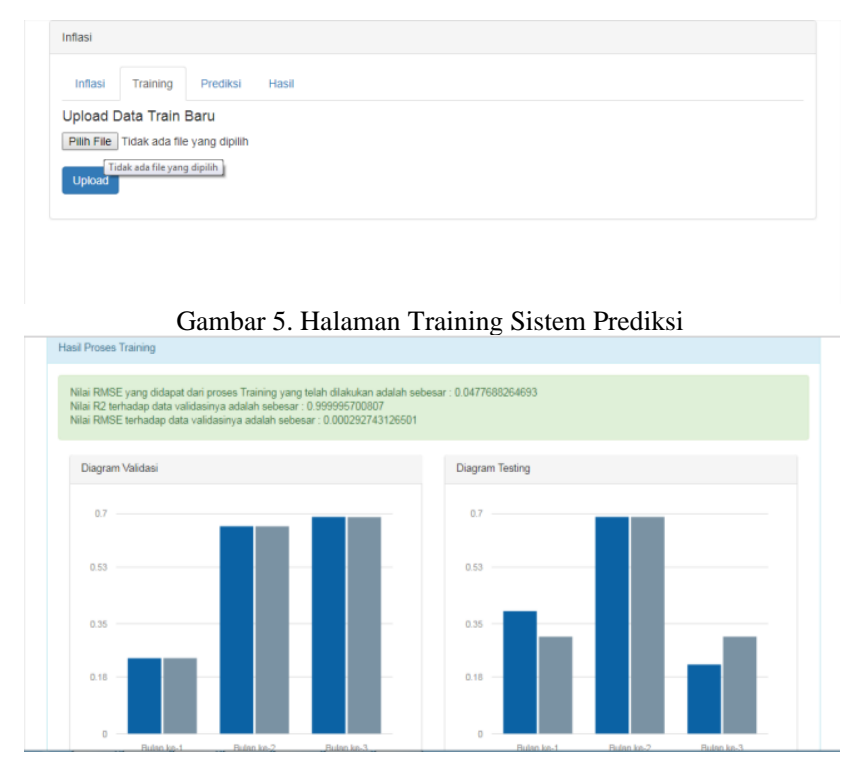

Gambar 1 Hasil Proses Training

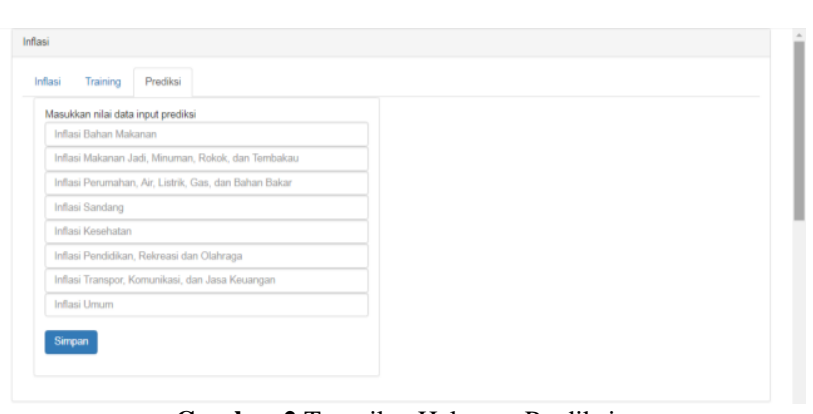

Gambar 2 Tampilan Halaman Prediksi

\section{KESIMPULAN}

Berdasarkan dari pembahasan dan hasil analisa percobaan yang sebelumnya telah dilakukan, maka dapat diambil kesimpulan bahwa: Hasil model prediksi yang paling baik dari percobaan terhadap data inflasi menurut kelompok komoditi dengan menggunakan metode SVR (Support Vector Regression) yaitu model dengan kombinasi parameter C sebesar 0,37, 
epsilon ( $(\varepsilon)$ sebesar 0,0001 dan gamma $(\gamma)$ sebesar 12,5365 dengan RMSE terhadap data validasinya sebesar 0.0011 dan $\mathrm{R}^{2}$ terhadap data validasinya sebesar 0.9999. Akurasi model prediksi yang didapatkan dari model yang telah dihasilkan terhadap data testingnya yaitu inflasi selama 3 bulan dari mei hingga juli 2017 adalah RMSE sebesar 0.0477 dengan hasil prediksi yang dihasilkan sudah cukup baik.

Pada penelitian selanjutnya diharapkan agar digunakannya algoritma lain yang dapat dikombinasikan dengan SVR sehingga nilai dari parameter yang digunakan dapat dipilih secara optimal dan lebih mudah. Selain itu, Penambahan jangka waktu yang lebih lama juga disarankan untuk melihat kinerja model terhadap data yang lebih beragam.

\section{DAFTAR PUSTAKA}

[1] Boediono, Teori pertumbuhan ekonomi / oleh Boediono. Yogyakarta: BPFE, 1985.

[2] Badan Pusat Statistik, Data Strategis BPS. Jakarta: Badan Pusat Statistik, 2011.

[3] Endri, "Analisis Faktor-Faktor yang Mempengaruhi Inflasi di Indonesia," Jurnal Ekonomi Pembangunan, vol. XIII, no. 1, pp. 1-13, April 2008.

[4] Agustini Tripena, "Peramalan Indeks Harga Konsumen dan Inflasi Indonesia dengan Metode Arima Box-Jenkins," Magistra, vol. XXIII, no. 75, Maret 2011.

[5] Nadia Roosmalita Sari, Wayan Firdaus Mahmudy, and Aji Prasetya Wibawa, "Mengukur Performa Model TSK Fuzzy Logic Menggunakan Faktor Eksternal untuk Peramalan Laju Inflasi," Jurnal Ilmu Komputer dan Teknologi Informasi, vol. 9, no. 1, pp. 27-32, Maret 2017.

[6] Vladimir N. Vapnik, The Nature of Statistical Learning Theory. Verlag: Springer, 1995.

[7] Christopher M. Bishop, Pattern Recognition and Machine Learning.: Springer, 2006.

[8] Nugroho Dwi S., "Penerapan Algoritma Support Vector Machine untuk Prediksi Harga Emas," Jurnal Informatika UPGRIS, vol. 1, pp. 10-19, Juni 2015.

[9] Indeks Harga Konsumen dan Inflasi Bulanan Indonesia. [Online]. https://www.bps.go.id/linkTabelStatis/view/id/907

[10] Inflasi Indonesia Menurut Kelompok Pengeluaran. [Online]. https://www.bps.go.id/linkTabelStatis/view/id/901 